\title{
Epidemiologia do trauma raquimedular cervical na zona norte da cidade de São Paulo
}

\author{
Ricardo Vieira Botelho*, Carla Maria Balieiro Abgussen*, Gustavo Campos Furtado \\ Pereira Machado*, Alexandre José Reis Elias*, Ana Amelia Benedito-Silva**, Lia Rita \\ Azeredo Bittencourt ${ }^{\star *}$, Emilio Afonso França Fontoura*
}

Trabalho realizado no Serviço de Neurocirurgia do Conjunto Hospitalar do Mandaqui e Departamento de Psicobiologia da UNIFESP - EPM, São Paulo, SP

\section{RESUMO}

Objetivos: Estudar a epidemiologia do paciente vitima de trauma raquimedular cervical na zona norte da cidade de São Paulo, na área definida como DIR IV e na região de Franco da Rocha, entre 1996 e 2000.

Métodos: Estudo parte retrospectivo, parte prospectivo, baseado em dados de protocolo padronizado para trauma raquimedular, consultas médicas e estudo de prontuários.

Casuística: 95 pacientes consecutivos foram estudados entre abril de 1996 e dezembro de 2000. Conclusões: A incidência de casos de trauma raquimedular geral estimada foi de 22,63 milhão/ano e de trauma cervical foi de 8,6 milhão/ano. A média mensal foi 84\% maior no ano de 1999 em comparação a 1996. Predominaram as quedas ao solo como causa. A média de idade foi de 35 anos. Quarenta e cinco por cento da amostra apresentava-se com menos de 30 anos. Quarenta e dois por cento dos pacientes apresentaram complicações potencialmente graves. A média de internação foi de 25,86 dias.

As lesões O-C1-C2 causaram dano neurológico menos freqüentemente que as C3-C7 (11,6\%/ $61,04 \%)$. As lesões que produziram deficit completo acima de C3 foram fatais. Mais de $60 \%$ dos pacientes com traumatismo C3-C7 apresentaram deficits neurológicos e 41,5\% apresentam paralisia, com nenhuma força evidente ao exame, com ou sem preservação sensitiva; $44 \%$ destes morreram. Um paciente teve piora neurológica antes da cirurgia e outro teve seu quadro neurológico piorado pela cirurgia.

O estado neurológico e o nível da lesão foram os fatores prognósticos mais importantes.

Os 95 pacientes utilizaram 77 sistemas de fixação e/ou halo-coletes.

\section{PALAVRAS-CHAVE}

Epidemiologia. Trauma raquimedular. Cidade de São Paulo.

\section{ABSTRACT}

Epidemiology of cervical spine injury in the north area of Sao Paulo City Objectives: To study the epidemiology of the cervical spine injury in the North Area of São Paulo City, from 1996 to 2000.

Method: retrospective study based on a standard protocol for spine injury, office records and spinal cord injury data bank.

Casuistic: All patients hospitalized for treatment between April, 1996 and December, 2000.

Conclusions: The incidence of cervical spinal cord injury was $8,6 / \mathrm{million} / \mathrm{year}$, and the overall incidence of the whole spine injury was 22,63/million/year (estimated). In 1999, there were 1,84 times more cervical spinal trauma patients than in 1996. Falls were the most important cause of the cervical spine cord injury. Car crash was in second place in order of frequency. Fourty-five percent of the patients were younger than 30 years. Fourty-two percent of the patients had important complications. The O-C1-C2 injuries caused less neurologic lesion than C3-C7 injuries. More than $60 \%$ of the patients with C3-C7 spine cord injury had neurological deficits and $41,5 \%$ had complete paralysis, with or without sensation preservation; $44 \%$ of them died. One patient presented neurological deterioration before surgery and one other after surgery. The neurological state and the level of the injury were the most important prognostics factors.

\section{KEYWORDS}

Epidemiology. Spinal injury. São Paulo City.

\footnotetext{
* Médico. Serviço de Neurocirurgia do Conjunto Hospitalar do Mandaqui.
}

** Pesquisadora da Associação Fundo de Incentivo à Psicofarmacologia do Departamento de Psicobiologia da UNIFESP - EPM. 


\section{Introdução}

O trauma raquimedular (TRM) é causa freqüente de invalidez e óbito. Quando ocorre na coluna cervical (TRMC), produz a maior morbimortalidade entre todas as localizações. O tratamento é prolongado e seu custo é alto. Nos EUA, uma internação hospitalar nessas situções custa em torno de 90 mil dólares ${ }^{9}$, e os cuidados médicos e sociais chegam a 1 milhão de dólares ${ }^{12}$ durante o restante da vida do paciente.

A incidência do trauma e suas repercussões individuais e sociais podem variar dependendo das formas de organização da ocupação urbana, dos hábitos e da educação de uma população. As informações epidemiológicas podem mostrar essas diferenças características e auxiliar a programar recursos materiais e físicos necessários ao tratamento e a prever o resultado da terapia e o prognóstico do trauma.

Para obter essas informações, foram estudadas as características epidemiológicas dos pacientes vítimas de trauma raquimedular cervical hospitalizados, provenientes de uma área geográfica definida da zona norte da cidade de São Paulo, tratada em uma única instituição, Conjunto Hospitalar do Mandaqui, entre 1996 e 2000.

\section{Pacientes e métodos}

Tipo do estudo: Parte retrospectivo e parte prospectivo.

Período do estudo: Foram estudados cinco períodos anuais: o primeiro período foi iniciado em $1^{\circ}$ de abril e terminado em 31 de dezembro de 1996 (9 meses), e os demais, iniciados em $1^{\circ}$ de janeiro e terminados em 31 de dezembro de cada ano (12 meses), entre 1997 e 2000 (12 meses).

Área de origem dos registros: A área estudada foi definida pela Secretaria de Saúde do Estado de São Paulo como DIR IV e a região de Franco da Rocha (Figura 1), com população estimada de 2.289 .585 pessoas (censo 1996).

Critérios de inclusão: Foram incluídos pacientes com TRMC grave provenientes da área acima discriminada e encaminhados ao Conjunto Hospitalar do Mandaqui, referência neurocirúrgica terciária. Esses foram candidatos ao tratamento cirúrgico se apresentassem instabilidade vertebral e/ou dano neurológico associado. O diagnóstico de instabilidade foi baseado nos critérios de White e cols. ${ }^{23}$ (Tabela 1). Aqueles tratados exclusivamente no setor de emergência e liberados não foram incluídos no estudo, assim como não o foram os traumatizados que não sobreviveram à fase aguda do trauma, no local do trauma ou no serviço de emergência.

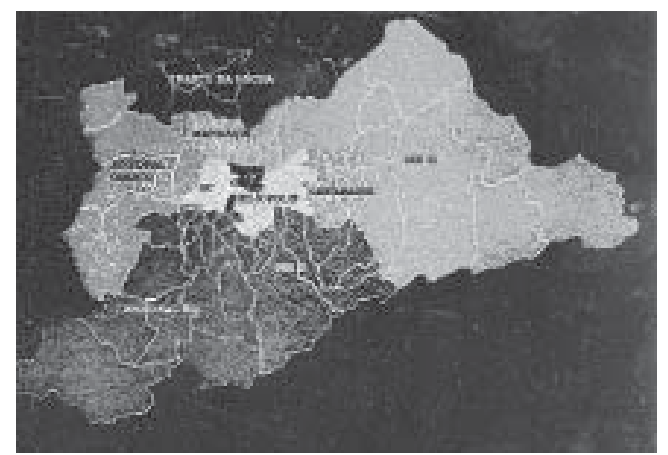

Figura 1 - Areas de referência neurocirúrgica da Secretaria do Estado da Saúde - A área estudada está representada pelas regiões de Franco da Rocha e Mandaqui.

\begin{tabular}{lc}
\hline \multicolumn{2}{c}{ Tabela 1} \\
Critérios de instabilidade \\
\hline Elementos & Valor em pontos \\
\hline Elementos anteriores destruídos ou & \\
incapazes de funcionar & 2 \\
Elementos posteriores destruídos ou & 2 \\
incapazes de funcionar & 2 \\
Translação relativa no plano sagital = 3,5 mm & 2 \\
Rotação relativa no plano sagital $=11^{\circ}$ & 2 \\
Teste de estiramento positivo & 2 \\
Dano medular & 1 \\
Dano radicular & 1 \\
Diminuição anormal do espaço discal & 1 \\
Carga antecipada perigosa & instável \\
\hline Total de 5 ou mais & \\
\hline
\end{tabular}

Adaptado de White A, Southwick WO, Panjabi MMP23

Os dados foram retirados de protocolos de evolução padronizada do TRMC (implantados para formação de banco de dados a partir de 1996), de análise de prontuários e arquivos de pacientes e, em menor proporção, de registros ambulatoriais.

Variáveis em análise: Foram estudadas as incidências mensais e anuais, as tendências, as causas, a morbidade neurológica, a mortalidade, as características antropológicas das pessoas em risco (idade e sexo), os tipos de tratamentos efetuados, os tempos de internação (tempo entre o trauma e a internação, entre o trauma e a cirurgia e entre a cirurgia e a alta). Os materiais de fixação espinhal utilizados, as complicações e a evolução também foram registrados.

Classificação do TRMC: Para a descrição dos dados, a coluna cervical foi dividida nos segmentos occipitoatlantoaxial (O-C1-C2) e subaxial (C3-C7).

Os tipos de lesão (fraturas ou fraturas/luxação) foram descritos segundo Anderson ${ }^{3}$, e acrescentadas as entidades hérnia discal traumática e ferimento por 
projétil de arma de fogo (FAF), para inclusão de todos os casos do estudo (Tabela 2).

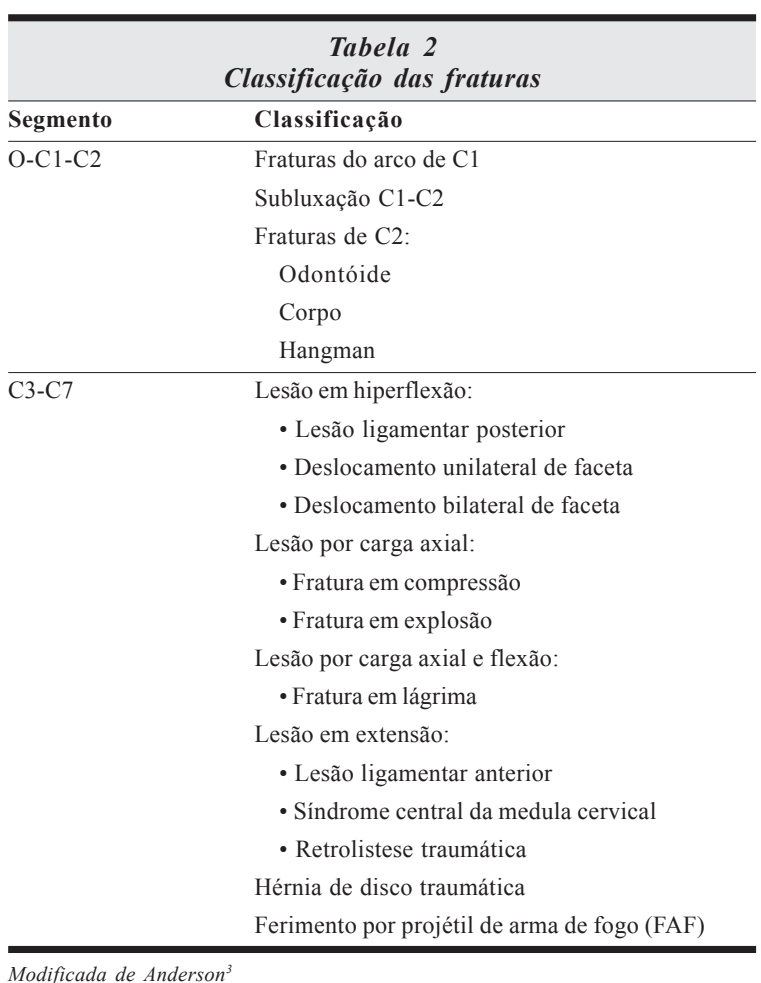

O estado neurológico foi classificado de acordo com os critérios da Associação Americana de Lesão Espinhal - ASIA-(Tabela 3).

\begin{tabular}{|c|c|}
\hline & $\begin{array}{c}\text { Tabela } 3 \\
\text { Escala de deficiência }- \text { ASIA* }\end{array}$ \\
\hline Grau & Quadro neurológico \\
\hline A & Ausência de função motora e sensitiva abaixo do nível de lesão \\
\hline B & $\begin{array}{l}\text { Ausência de função motora abaixo do nível de lesão com } \\
\text { preservação sensitiva }\end{array}$ \\
\hline $\mathrm{C}$ & $\begin{array}{l}\text { Preservação parcial da função motora, com força capaz de vencer } \\
\text { a gravidade }\end{array}$ \\
\hline $\mathrm{D}$ & $\begin{array}{l}\text { Preservação parcial da função motora, com força capaz de vencer } \\
\text { a resistência }\end{array}$ \\
\hline $\mathrm{E}$ & Função neurológica normal \\
\hline
\end{tabular}

Estatística: As incidências foram analisadas por estatística descritiva com médias, amplitude e desviospadrão. A distribuição das freqüências mensais/anuais foi comparada com teste do $\mathrm{X}^{2}$ da amostra anual de 1997 a 2000, evitando-se os dados ausentes dos três primeiros meses do ano de 1996.

\section{Resultados}

Incidência: Entre abril de 1996 e dezembro de 2000, 95 pacientes com TRMC foram internados. Onze pacientes nos nove meses de 1996, 18 pacientes durante o ano de 1997, 22 em 1998, 27 em 1999 e 17 em 2000 (Tabela 4).

\begin{tabular}{|c|c|c|c|c|c|}
\hline \multicolumn{6}{|c|}{$\begin{array}{c}\text { Tabela } 4 \\
\text { Distribuição mensal 1996-2000 (em número de casos) }\end{array}$} \\
\hline & 1996 & 1997 & 1998 & 1999 & 2000 \\
\hline Jan & & 1 & 1 & 9 & 3 \\
\hline $\mathrm{Fev}$ & & 0 & 3 & 1 & 0 \\
\hline Mar & & 0 & 0 & 1 & 2 \\
\hline Abril & 2 & 1 & 2 & 3 & 0 \\
\hline Maio & 3 & 1 & 3 & 1 & 1 \\
\hline Jun & 1 & 2 & 1 & 2 & 1 \\
\hline Jul & 0 & 1 & 1 & 0 & 0 \\
\hline Ago & 0 & 1 & 2 & 0 & 0 \\
\hline Set & 1 & 3 & 3 & 2 & 4 \\
\hline Out & 1 & 2 & 3 & 2 & 1 \\
\hline Nov & 2 & 4 & 1 & 1 & 3 \\
\hline Dez & 1 & 2 & 2 & 5 & 2 \\
\hline Total & 11 & 18 & 22 & 27 & 17 \\
\hline Mensal & 1,22 & 1,5 & 1,83 & 2,25 & 1,41 \\
\hline Variação & $(0-3)$ & $(0-4)$ & $(0-3)$ & $(0-9)$ & $(0-4)$ \\
\hline
\end{tabular}

A média de incidências anuais, entre os anos de 1997 e 2000, foi de 21, e a média de incidências mensais entre abril de1996 e dezembro de 2000 foi de 1,64/mês.

A incidência do TRMC/milhão de habitantes/ano foi de 8,6. Como o TRMC perfez 38\% de nossa casuística total dos TRM, a incidência do TRM geral no período pode ser estimada em 22,63/milhão de habitantes/ano.

Tendências: As tendências de ocorrência mensal observadas nos cinco períodos podem ser vistas no gráfico 1a, e a distribuição de freqüências com médias e desvios-padrão, no gráfico 1b. Comparadas as médias

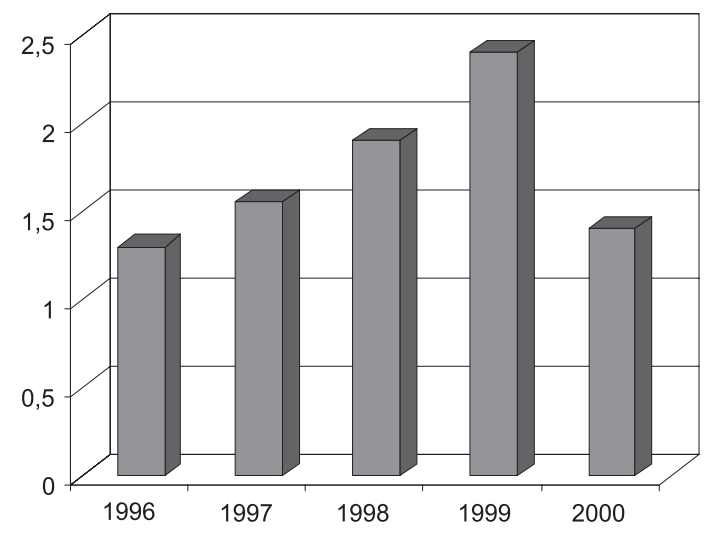

Gráfico 1a - Incidências mensais entre 1996 e 2000. 


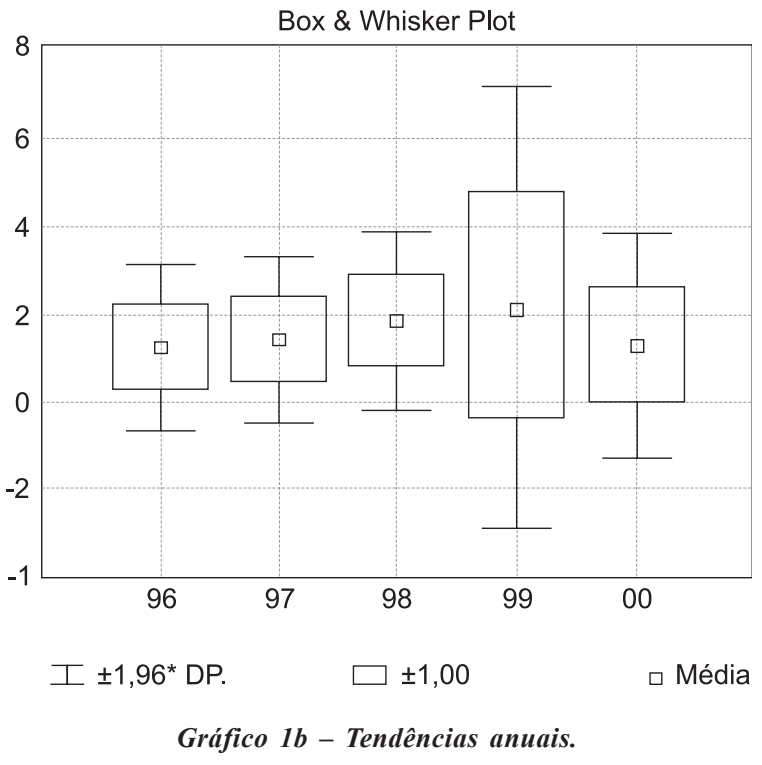

anuais dos quatro períodos de 12 meses (1996 a 2000), não houve diferença estatisticamente significativa no nível de significância de 0,05 . $\left(X^{2}=2,95 ; p<0,39\right)$.

Pessoas em risco: A média das idades dos pacientes foi de 35,13 anos $\pm 16,15$. A faixa etária mais acometida foi aquela entre 20 e 40 anos (mais de $45 \%$ dos pacientes). Quarenta e cinco por cento (43/95) dos pacientes tinham menos que 30 anos (Gráfico 2). A relação homens/mulheres foi de 82/13 (6,3/1).

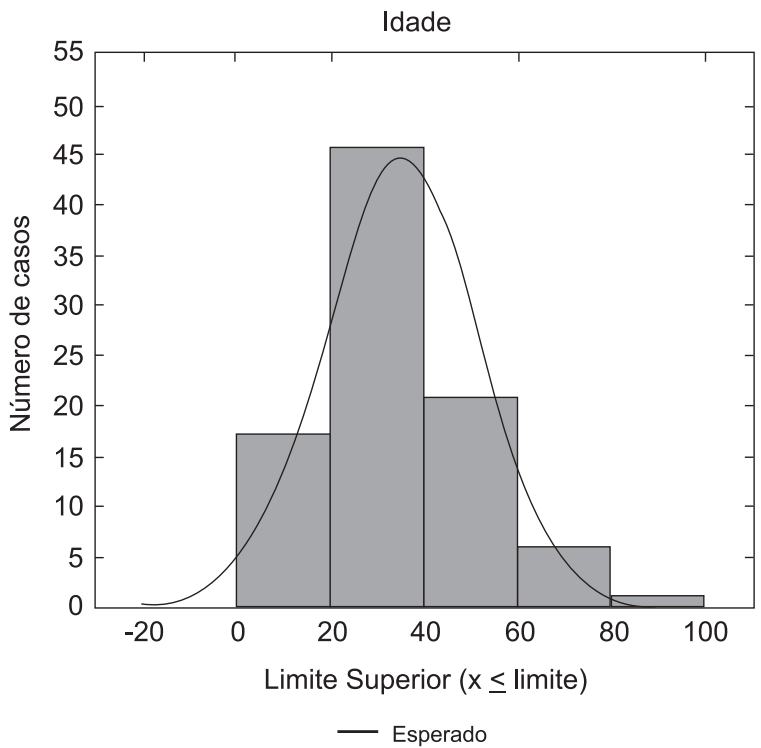

Gráfico 2 - Distribuição por idade.
Locais de origem: A origem dos pacientes por bairros está registrada a seguir. Os números entre parênteses descrevem a quantidade de pacientes por bairro. O bairro sem tal especificação teve apenas um caso no período estudado: Alpes do Jaraguá, Alto do Mandaqui, Bortolândia, Cambuci, Casa Verde Jardim Monteiro, Jardim Antárctica, Jardim Brasil, Jardim Constância, Jardim Damasceno, Jardim dos Reis, Jardim Guapira, Jardim Guarani, Jardim Jaraguá, Jardim Luciana, Jardim Monte Kemel, Jardim Panamericano, Jardim Peri Alto, Jardim Piratininga, Jardim São Estevão, Jardim Santa Cruz, Jardim Suíço, Jordanésia, Mairiporã, Mandaqui, Parada Inglesa, Parque Mandaqui, Pirituba, Parque Edson, Rodovia Fernão Dias, Santana, São Miguel, Santana do Parnaíba, Sé, Taboão, Taipas, Tucuruvi, Vila Amália, Vila Nova Paulicéia, Vila Penteado, Vila Ede, Vila Roseira, Vila Regente Feijó, Vila Nova Cachoeirinha, Brasilândia (2), Caieiras (2), Vila Maria Alta (2), Vila Albertina (2), Franco da Rocha (3), Freguesia do Ó (3), Imirim (3), Penha (3), Guarulhos (4), Francisco Morato (5), Lauzane Paulista (6), Jardim Peri (7), Desconhecido (9).

Causas: A tabela 5 descreve as causas do TRMC.

\begin{tabular}{lc}
\hline \multicolumn{2}{c}{ Cabela 5} \\
\\
\hline Causas \\
\hline Acidente motociclístico \\
Desconhecidas & N \\
Agressão & $3(3,1 \%)$ \\
Projétil de arma de fogo & $5(5,2 \%)$ \\
Atropelamento & $5(5,2 \%)$ \\
Mergulho em água rasa & $5(5,2 \%)$ \\
Acidente automobilístico & $10(10,5 \%)$ \\
Quedas & $14(14,7 \%)$ \\
\hline Total & $22(23 \%)$ \\
\hline
\end{tabular}

Distribuição segundo a localização da lesão: Os traumas O-C1-C2 corresponderam a 18,9\% (com 18 casos) dos TRMC ; em 81,1\% (77 casos) a lesão ocorreu na coluna cervical subaxial (Figura 2).

Os traumatismos em O-C1-C2 tiveram a seguinte distribuição:

- lesões em C1 com 2 casos (11\%): 1 caso de fratura de Jefferson (explosão de C1) e 1 caso de fratura combinada $\mathrm{C} 1-\mathrm{C} 2$;

- subluxação C1-C2 com 2 casos (11\%);

- espondilolistese traumática do axis - fratura do enforcado - com 8 casos (44\%) (Figura 3); 


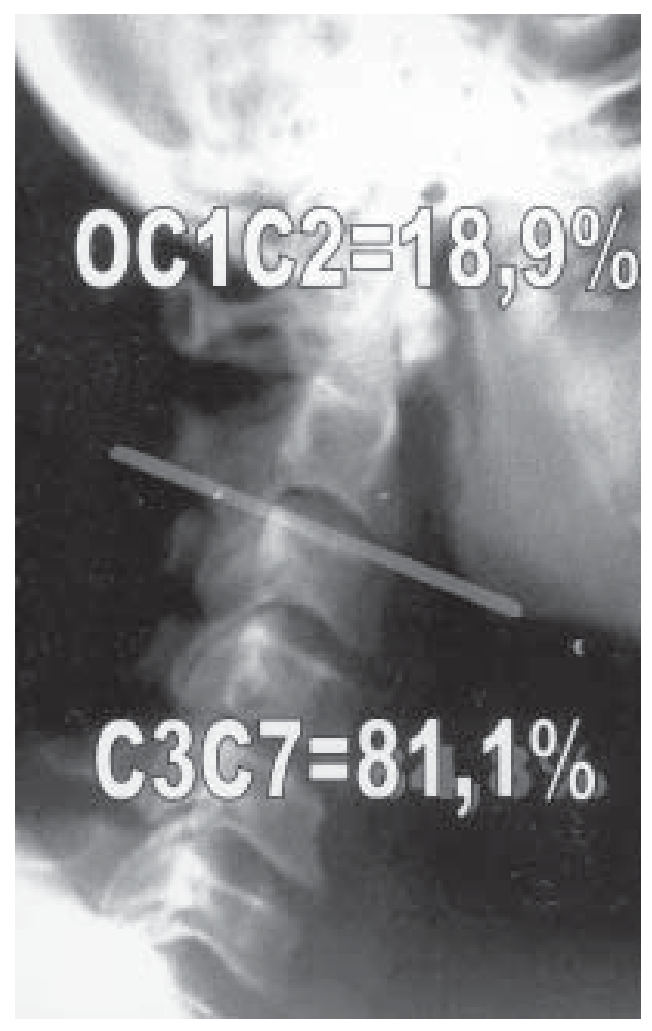

Figura 2 - Distribuição dos traumas raquimedulares cervicais nos segmentos $\mathrm{O}-\mathrm{C1}-\mathrm{C2}$ e $\mathrm{C3}-\mathrm{C} 7$.

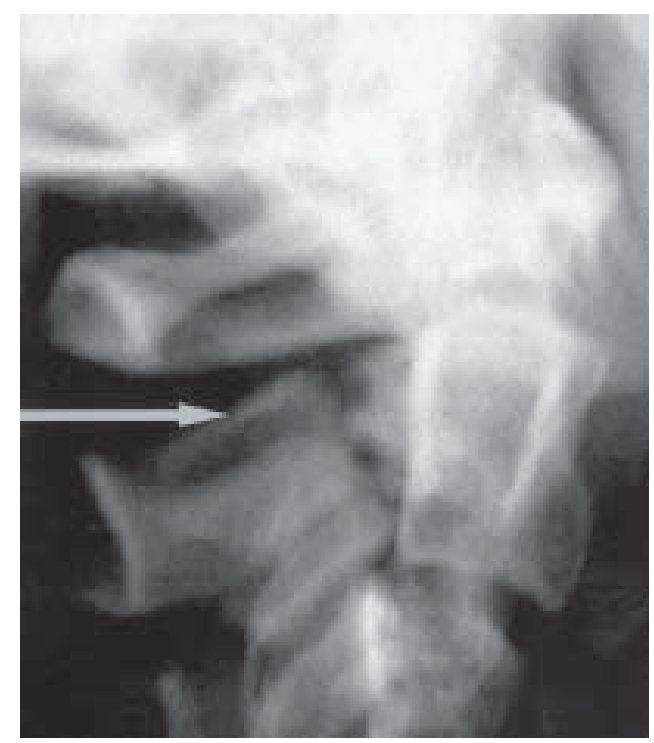

Figura 3 - Espondilolistese traumática do axis - fratura do enforcado (seta).

- fraturas do odontóide tipo II com 6 casos (35\%) (Figura 4).

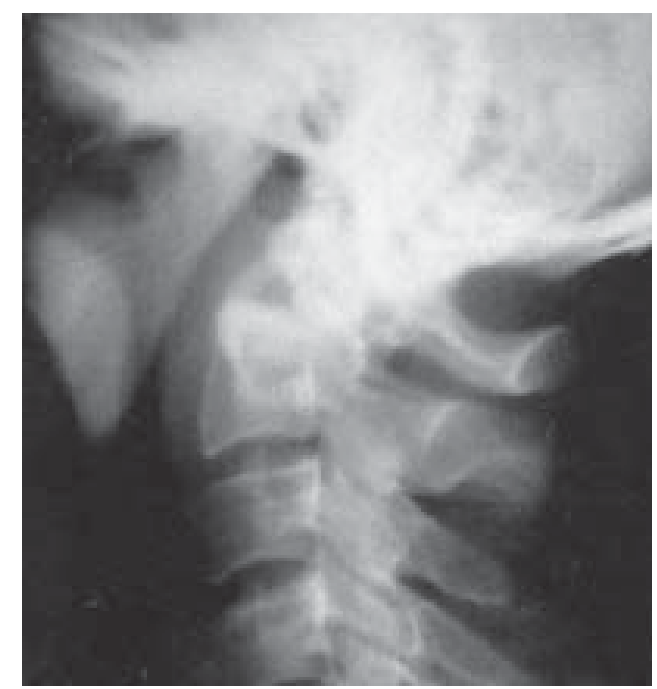

Figura 4 - Fratura do odontóide tipo II.

Os traumatismos observados em $\mathrm{C} 3-\mathrm{C} 7$ foram assim distribuídos:

- hiperflexão (Figura 5) foi o tipo mais freqüente com 30 casos (38\%): 22 casos (28\%) de lesão

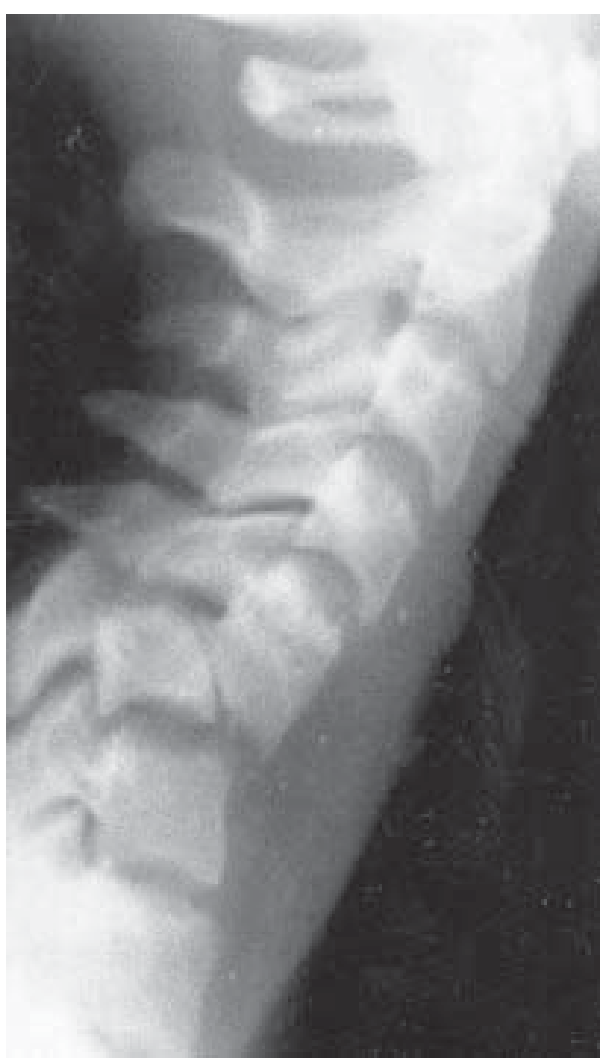

Figura 5 - Fratura em hiperflexão C5-C6. 
ligamentar posterior; 4 (5\%) de bloqueio facetário unilateral; 4 (5\%) de bloqueio facetário bilateral;

- carga axial (Figura 6): foi observada em 25 casos (32\%): 24 casos (31\%) de fratura explosão e 1 (1,05\%) de fratura compressão;

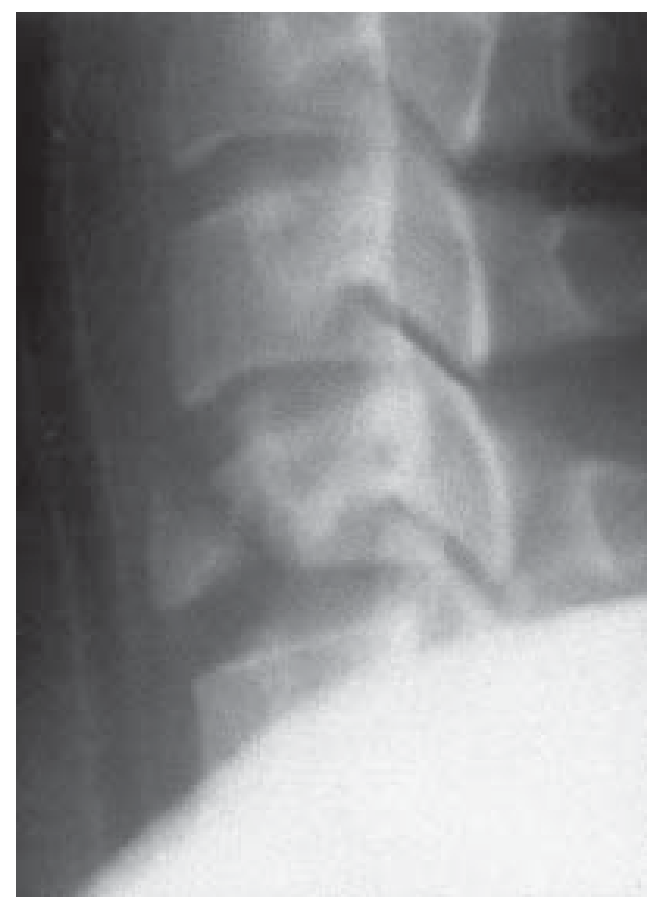

Figura 6 - Fratura por carga axial.

- hiperextensão (Figura 7): em 10 casos (12,9\%): em $8(10,3 \%)$ de lesões sem evidente alteração óssea nem ligamentar e 2 (2,51\%) de lesão ligamentar anterior (extensão/distração);

- $\quad$ carga axial e flexão (Figura 8): em 3 (3,9\%);

- ferimento por projétil de arma de fogo em 6 $(7,79 \%)$;

- hérnia do núcleo pulposo em 2 (2,60\%);

- fraturas múltiplas do processo espinhoso em 1 (1,39\%).

Morbidade neurológica: Traumatismo O-C1-C2 Todos os pacientes tinham exame neurológico normal, exceto três. Dois destes se apresentavam tetraplégicos, (ASIA A), ambos apresentando subluxação C1-C2. O outro se apresentava em ASIA C, com fratura do odontóide tipo II, e evoluiu para ASIA E ao final da internação.

Traumatismo C3-C7 - 34 (44\%) pacientes tinham lesão completa (ASIA A), 23 (29,87\%) estavam intactos (ASIA E), 4 (5,19\%) foram classificados em ASIA B, 5

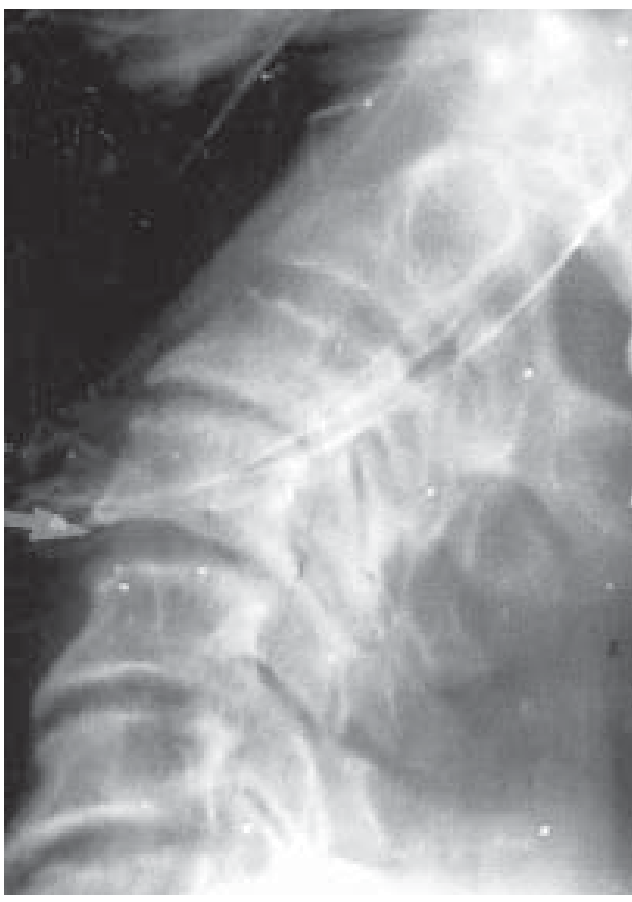

Figura 7 - Fratura em hiperextensão C4-C5 (seta).

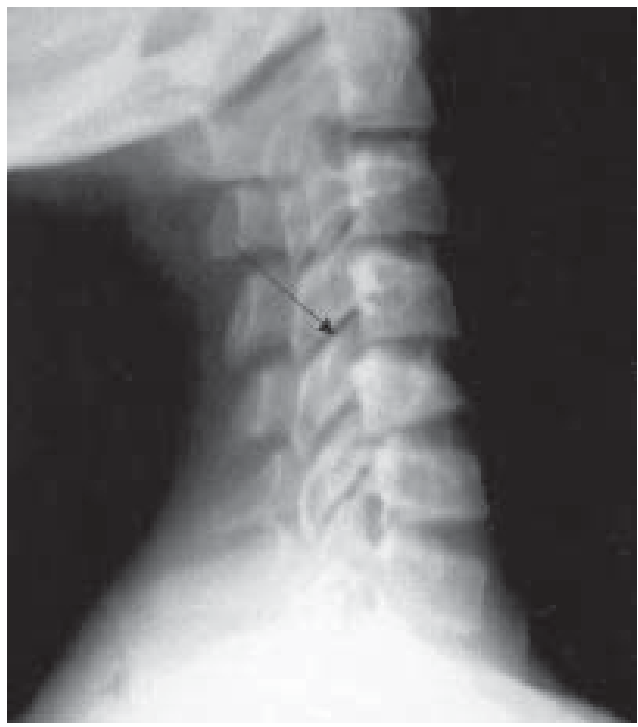

Figura 8 - Fratura por carga axial + flexão.

$(6,49 \%)$ em ASIA C e 5, em ASIA D. Seis pacientes se apresentaram com deficit motor mais intenso nos membros superiores que nos inferiores, estado neurológico de síndrome centromedular $(7,79 \%)$ (Gráfico 3). 


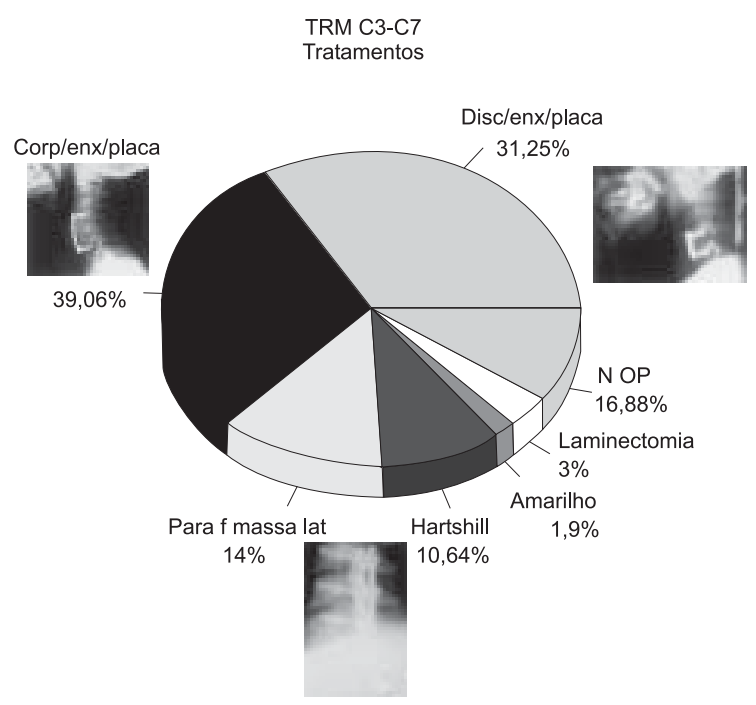

Gráfico 3 - Morbidade neurológica.

Tipos de tratamento e sistemas de fixação utilizados: Dos pacientes com TRMC do tipo O-C1-C2, 2 evoluíram para óbito antes da cirurgia; 7 foram tratados com halo-colete ou colar cervical e 9 foram tratados cirurgicamente: 3 deles com parafuso no odontóide (Figura 9), 3 com retângulo de Hartshill, 2 com amarrilho com cabos flexíveis e 1 com parafuso transarticular C1-C2 (Figura 10).

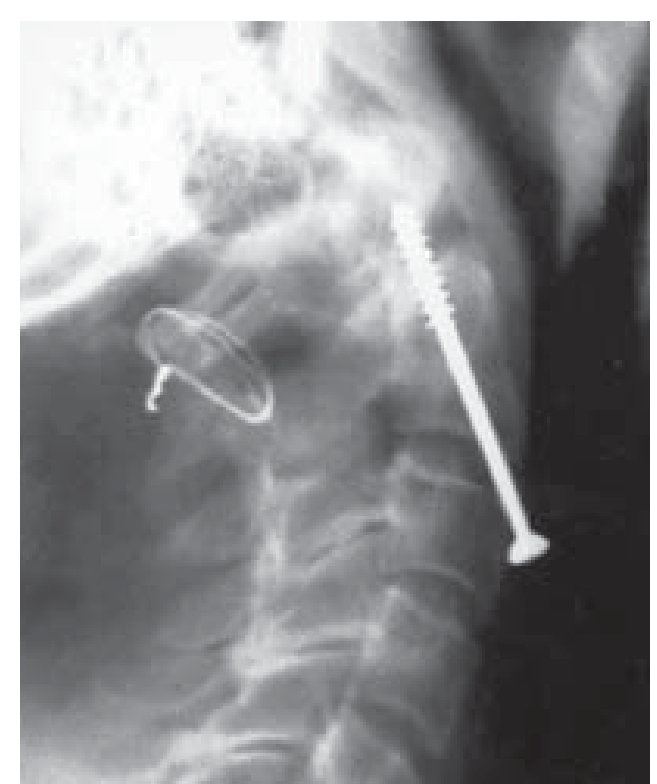

Figura 9 - Tratamento cirúrgico por via anterior com parafuso no odontóide em paciente com fratura de odontóide tipo II e falência de fixação posterior.

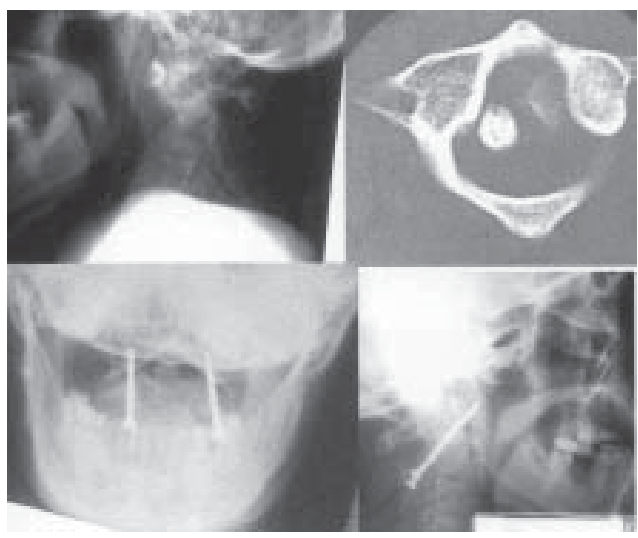

Figura 10 - Tratamento cirúrgico por via posterior com parafusos transarticulares $\mathrm{C1}-\mathrm{C} 2 \mathrm{em}$ paciente com fratura de odontóide tipo II e subluxação C1-C2.

Dos casos de TRMC C3-C7, 64 dos 77 pacientes $(83,11 \%)$ foram operados por uma das duas vias relacionadas abaixo (Gráfico 3 e Figura 11):

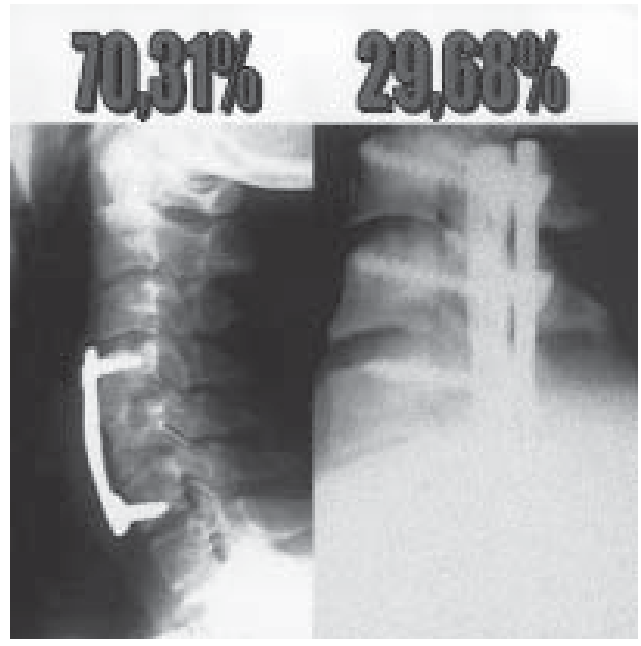

Figura 11 - Distribuição dos pacientes segundo a via cirúrgica utilizada (via anterior $=70,31 \%$; via posterior $=29,68 \%$ ).

A) Via anterior: 70,31\% (45 casos) das cirurgias foram feitas por via anterior. Do total, 39,06\% foram submetidos à corpectomia para descompressão de fragmentos ventrais ao saco dural (fraturas explosão ou corpo vertebral desviado posteriormente em traumas por compressão axial e flexão). Em 31,25\% do total de cirurgias, foi realizada discectomia, com enxerto ósseo e placa para artrodese em pacientes apresentando lesões por hiperflexão redutíveis. Todos os pacientes com subluxações reduzidas e que não tinham contraindicações para via anterior utilizaram essa via. 
B) Via posterior: 29,68\% (19 casos) dos pacientes foram operados por via posterior. Em 9, utilizaram-se sistemas de parafusos e placa na massa lateral e/ou pedículo de T1; em 7, usou-se retângulo de Hartshill com amarrilho sublaminar; 2 foram submetidos à laminectomia para tratamento do FAF e uma paciente foi submetida à facetectomia para desbloqueio facetário e subseqüente via anterior, em outro tempo. Neste caso não houve artrodese posterior por risco de infecção do sistema devido a úlcera de pressão e infecção da pele.

Sistemas de fixação utilizados: Nos 95 pacientes estudados foram usados 77 sistemas de fixação, incluindo-se os halo-coletes, enumerados na tabela 6 .

\begin{tabular}{lc}
\hline \multicolumn{2}{c}{ Tabela 6} \\
Sistemas de fixação & utilizados \\
\hline Sistemas de fixação & Número de casos \\
\hline Parafuso canulado 3,5 mm para odontóide & 3 \\
Parafuso canulado 3,5 mm C1-C2 & 1 \\
Retângulo cervical com amarrilho sublaminar & 10 \\
Cabos flexíveis para amarrilho sublaminar & 2 \\
Colar/halo-colete & 7 \\
Placa cervical anterior com parafusos & 45 \\
Placa cervical posterior (Roy-Camille) com parafusos & 9 \\
\hline
\end{tabular}

Pacientes não operados: Dos 18 casos de lesões da transição craniocervical (O-C1-C2), 9 pacientes não foram operados. Dois faleceram antes da cirurgia e 7 foram tratados com colar cervical ou halo-colete.

Entre os 77 casos de lesão C3-C7, 13 (16,88\%) não foram operados: 5 destes porque não sobreviveram ao trauma, 5 porque apresentaram lesão medular sem acometimento ósseo ou ligamentar, 1 paciente que apresentava fratura compressão, 1 paciente que teve hérnia discal traumática com melhora progressiva e outro que apresentava fraturas múltiplas de processos espinhosos, nos quais a instabilidade foi excluída.

Complicações: Virtualmente todos os pacientes apresentando paralisia tiveram complicações cutâneas por úlcera de pressão. Além disso, 44,21\% dos pacientes tiveram complicações em outros órgãos e sistemas (Tabelas 7a e 7b). Vários pacientes tiveram múltiplas complicações.

Tempo de internação: $O$ tempo médio decorrido entre o trauma e a internação foi de 4,6 dias; entre a internação e a cirurgia foi de 11,95 dias; entre a cirurgia e a alta, 19 dias; o tempo médio total de internação foi de 25,86 dias (Tabela 8).

Mortalidade: Dezesseis (16,8\%) entre 95 pacientes evoluíram para óbito. A mortalidade relativa oscilou entre $14 \%$ e $18 \%$ nos cinco períodos estudados (Gráfico 4).

\begin{tabular}{lc}
\hline \multicolumn{1}{c}{$\begin{array}{c}\text { Tabela } \\
\text { Complicações } \text { clínicas }\end{array}$} & \\
\hline Complicações & N \\
\hline Pneumonia & 11 \\
Trombose venosa profunda & 4 \\
Tromboembolismo pulmonar & 4 \\
Traqueostomia & 4 \\
Fístula liquórica (ferimento por arma de fogo) & 1 \\
Hemorragia digestiva alta & 2 \\
Gastrectomia & 1 \\
Infecção do trato urinário & 3 \\
Derrame pleural & 1 \\
Óbitos & 16 \\
\hline
\end{tabular}

Tabela $7 b$

Complicações neurológicas e/ou do tratamento

\begin{tabular}{ll}
\hline Complicações & N \\
\hline Piora neurológica pré-operatória & 1 \\
Piora neurológica pós-operatória & 1 \\
Dissociação C1-C2 após tração & 1 \\
Lesões irredutíveis ou redução incompleta & 2 \\
Afonia & 1 \\
Perda fixação do halo-colete & 3
\end{tabular}

\begin{tabular}{c} 
Tabela 8 \\
Periodos de internação \\
\hline Tempo médio decorrido entre o trauma e a internação: \\
$\mathrm{X}=4,6 \pm 22,31$ dias $(0-190)$ \\
Tempo médio entre a internação e a cirurgia: \\
$\mathrm{X}=11,95 \pm 15,473(0-100)$ \\
Tempo médio entre a cirurgia e a alta: \\
$\mathrm{X}=19 \pm 28,7(0-127)$ \\
Tempo médio total de internação: \\
$\mathrm{X}=25,86 \pm 27,32814(2-138)$
\end{tabular}

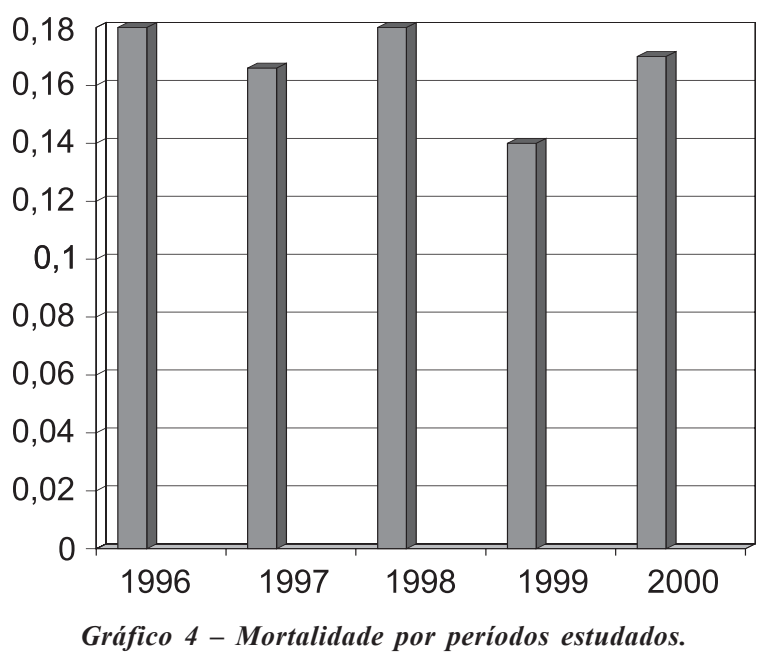


Todos os pacientes que evoluíram para óbito apresentavam lesão completa (ASIA A). Nenhum paciente com força evidenciável ao exame físico morreu. Dos 36 pacientes classificados em ASIA A, 16 (44\%) morreram.

A) O-C1-C2: Dois pacientes se apresentaram em ASIAA, com subluxações $\mathrm{C} 1-\mathrm{C} 2$, evoluindo para óbito.

B) C3-C7: 14 pacientes evoluíram para óbito (14/ $77=18,18 \%) ; 6$ tiveram lesões em hiperflexão, 6 tiveram fratura em carga axial (explosão) e 2 pacientes tiveram trauma em extensão (lesão ligamentar anterior).Todos foram classificados como ASIAA (Tabela 9).

\begin{tabular}{|c|c|c|}
\hline \multicolumn{3}{|c|}{$\begin{array}{c}\text { Tabela } 9 \\
\text { Mecanismos e niveis dos traumas nos casos fatais }\end{array}$} \\
\hline Mecanismo & Nível & $\mathbf{N}$ \\
\hline Subluxação & $\mathrm{C} 1-\mathrm{C} 2$ & 2 \\
\hline \multirow[t]{2}{*}{ Hiperflexão } & C5-C6 & 2 \\
\hline & C6-C7 & 4 \\
\hline \multirow[t]{3}{*}{ Carga axial } & $\mathrm{C} 5$ & 4 \\
\hline & C6 & 1 \\
\hline & $\mathrm{C} 5$ e $\mathrm{C} 6$ & 1 \\
\hline Extensão & C4-C5 & 2 \\
\hline
\end{tabular}

Evolução neurológica: Trinta e seis pacientes se apresentaram em ASIA A (Gráfico 3). Dezesseis destes faleceram. Um paciente deu entrada em ASIAA, evoluiu para $\mathrm{C}$ durante a internação e deambulou com auxílio na alta. Os demais permaneceram em $\mathrm{A}$.

Um paciente intacto (ASIA E) teve piora pósoperatória (ASIA C), permanecendo com monoparesia braquial esquerda durante a evolução.

Um paciente teve piora da força na mão esquerda antes da cirurgia, tendo sido operado em caráter de urgência, e recuperou-se parcialmente até a alta.

Os pacientes com lesão incompleta melhoraram durante a internação, em média um grau na escala ASIA.

\section{Discussão}

A primeira e fundamental questão em todo estudo epidemiológico é a verdadeira representação da realidade a partir da amostragem. Existem duas fontes nas quais podem ser obtidas informações no campo da saúde: os estabelecimentos onde as pessoas vão buscar assistência médica e a própria comunidade ${ }^{5,7}$.
O trabalho epidemiológico ideal sobre o tema em questão deveria ter a contagem de todos os traumas em uma população completamente contada ou estimada. $\mathrm{Na}$ comunidade isso é difícil ${ }^{9}$. Os trabalhos que se baseiam em registros de internações podem conter inadequações: os pacientes que morrem antes do atendimento hospitalar, assim como aqueles que sofrem o traumatismo em áreas distantes da sua moradia e aqueles que recebem altas atípicas (a revelia ou a pedido), não são computados. Como o TRMC é patologia grave, a maioria dos pacientes será levada aos hospitais.

Grande parte dos trabalhos epidemiológicos de TRM se baseia nos atendimentos hospitalares ${ }^{13}$. Em vários estados americanos, a notificação do TRM é compulsória. Em nosso país, isso não ocorre.

A gravidade do TRMC nos levou a estudá-lo especificamente.

Em São Paulo, os acidentes em via pública são socorridos pelos serviços de resgate, que são baseados em uma referência de atendimento hospitalar pública de emergência. Em virtude dessa vinculação, a maioria dos casos de traumatismos será atendida nesses serviços. Os pacientes associados à rede privada de atendimento podem ou não ser transferidos para esta. A quantidade de transferências para a rede privada é pequena em razão da instabilidade do quadro clínico geral ou da instabilidade vertebral associada, o que dificulta a remoção na fase aguda. Da mesma forma, a transferência para referências quaternárias (Universitárias) não foi feita em nenhum caso. Isso assegura que a grande maioria dos TRM da região analisada tenha sido atendida no hospital do estudo.

Assim, como na maioria dos trabalhos, apenas os sobreviventes ao trauma inicial foram computados. $\mathrm{O}$ diagnóstico das fatalidades pré-hospitalares tem sido descrito em estudos de necrópsias, e não nos estudos epidemiológicos.

Os TRM de evolução fatal antes do atendimento pré-hospitalar ocorrem freqüentemente nos casos de lesões cervicais altas, sendo C2 o nível mais acometido, por ser o local vulnerável a lesões dessa natureza ${ }^{6,14}$.

A incidência do TRMC observada em nosso estudo foi de 8,17/ milhão de habitantes/ano, e a do TRM geral foi de 21,5. Estes valores são inferiores aos de várias estatísticas americanas, que variam de 29 a 50/milhão de habitantes/ano ${ }^{13}$.

Não houve diferenças significativas anuais entre 1997 e 2000 ( $p<0,05)$. Porém, o ano de 1999 teve uma incidência mensal 1,84 vez maior que a incidência do ano de 1996. Do ponto de vista de planejamento hospitalar, $84 \%$ de diferença entre um ano e outro pode ser economicamente importante. Alguns serviços públicos baseiam suas provisões de acordo com o consumo do último ano. Em virtude da grande variação 
observada, essa previsão deveria ser baseada antes nas medidas de dispersão dos dados estatísticos.

A região estudada é composta de bairros residenciais e todos os casos foram provenientes da zona urbana. Foram identificados 55 sítios diferentes (bairros) de origem dos pacientes com TRMC.

A cor e os dados étnicos não foram estudados pela falta de fidedignidade dos registros.

As causas de TRM nos EUA são, por ordem de freqüência, o acidente automobilístico (45\%), as quedas $(22 \%)$, os esportes (14\%) e as lesões associadas à violência $(14 \%)^{9}$. Em nosso meio, as quedas foram as maiores causadoras (29\%), enquanto o acidente de automóvel causou $22 \%$ destas. Das quedas, a queda de laje foi a mais freqüente (7,3\%). Mergulho em água rasa foi a terceira causa, com pouco menos de $15 \%$, sendo potencialmente evitável por programas de segurança nos locais do trauma. Ferimento por projétil de arma de fogo contribuiu com 5\% das causas de TRMC. Provavelmente, essa distribuição das causas é reflexo da forma de ocupação urbana e do funcionamento do sistema viário da região em estudo.

Como a maior causa é a queda ao solo, sugere-se que os TRMC foram acidentes circunstanciais, localmente produzidos.

O TRM é comumente descrito como incidente preferencialmente em jovens. Dois terços dos TRM ocorrem em indivíduos abaixo dos 30 anos, com média de idade de 30 anos, mediana de 25 e moda de $19^{19}$. Em um estudo, três picos de incidência etária foram aparentes: 15 a 24,45 a 54 e maior que 75 anos $^{11}$.

A idade de maior acometimento pode diferir conforme o país. Zizeli e cols. ${ }^{24}$ encontraram um pico de incidência entre 30 a 39 anos, seguido de 40 a 49 e 20 a $29^{24}$. Em nossa amostra, a média de idade foi de 35 anos. A maior parte dos traumas ocorreu em indivíduos entre 20 e 40 anos, mas apenas $45 \%$ do total tinha menos de 30 anos. Um segundo pico de incidência do TRMC em torno dos 50 anos foi encontrado.

Vários estudos têm demonstrado predomínio do sexo masculino, numa proporção três a quatro vezes maior. Em nossa amostra, a relação homens/mulheres foi de $6,3 / 1$.

Uma parcela de nossos pacientes não foi hospitalizada na fase aguda do trauma. Esses se apresentaram com instabilidade mecânica de primeiro grau ${ }^{8} \mathrm{e}$ procuraram o hospital por dor ou deformidade tardia (instabilidade). A inclusão desses pacientes aumentou o tempo decorrido entre o trauma e a internação. Isso é freqüentemente verificado em traumatismo na região $\mathrm{O}-\mathrm{C} 1-\mathrm{C} 2$, que menos comumente causa deficits. Além disso, esses pacientes não foram tratados em caráter de emergência, mas somente quando houvesse estabilidade clínica.
O trabalho original de Marshall e cols. ${ }^{15}$, prospectivo, multicêntrico, analisando a deterioração neurológica durante a evolução do TRM, concluiu que os pacientes tratados na fase precoce, antes de cinco dias desde o trauma, evoluíam pior que os tratados após esses cinco dias. Vaccaro e cols. ${ }^{20}$, uma década depois, estudaram a evolução neurológica da cirurgia precoce (nas primeiras 72 horas) e cirurgia tardia (após cinco dias), e concluíram que não havia benefício neurológico nos pacientes operados precocemente, mas também não demonstraram os malefícios da cirurgia precoce descritos por Marshall ${ }^{15}$. Esses resultados têm mudado recentemente e demonstram que a cirurgia precoce pode ser feita sem complicações adicionais ${ }^{22}$, tendo sido defendida em alguns trabalhos ${ }^{17}$.

$\mathrm{O}$ efeito da cirurgia em melhorar deficits neurológicos, quando realizada na fase hiperaguda (nas primeiras 8 horas), é desconhecido. Não há, até o momento, evidências de que a cirurgia consiga melhorar o deficit neurológico na lesão completa ${ }^{21}$. A cirurgia de urgência em pacientes com TRMC esteve condicionada, em nossa casuística, àqueles que pioraram durante o tratamento e foi realizada em um único caso, de paciente em ASIA E que apresentou piora da força em membro superior. Os demais foram operados assim que tiveram estabilidade clínica e alinhamento vertebral ou definição sobre a impossibilidade de redução não cirúrgica.

No trabalho de Griffin, Opitz e Kurland ${ }^{11}$, a média de tempo de internação foi de 67 dias (4 a 100), incluindo cuidados de reabilitação. O tempo médio de internação em nosso estudo foi de 25,86 $\pm 27,32$ ( 2 a 138) dias, computando-se apenas o período hospitalar do tratamento.

O índice de complicações que observamos em nosso estudo foi alto $(44,21 \%)$. Virtualmente, todo paciente com lesão completa teve escara de decúbito. Fora estas, a complicação mais freqüente foi pulmonar, seguida pelas vasculares, gástricas e urinárias. Úlceras de pressão, urosepse, atelectasias, pneumonias e trombose venosa profunda são as complicações mais freqüentes descritas no trabalho de Maynard ${ }^{16}$, assim como em nosso estudo ${ }^{16}$. As complicações são causadas por imobilidade muscular, hipoventilação alveolar, decúbito imobilizado ativa ou passivamente no leito e como decorrência direta da lesão medular.

Entre as complicações decorrentes do próprio tratamento, houve perdas de fixação de halo-colete em três e, em duas, as lesões foram irredutíveis pela tração. Um paciente apresentou dissociação atlantoaxial vertical $^{4}$ após tração para subluxação C1-C2.

Dois pacientes apresentaram piora neurológica. Um deles teve piora espontânea antes da cirurgia e foi 
operado de urgência. Um paciente teve o deficit motor piorado após a cirurgia. Este, em ASIA E no préoperatório, evoluiu para ASIA C, tendo recuperação parcial durante a evolução.

As lesões O-C1-C2 causaram dano neurológico menos freqüentemente que as C3-C7 (11,6\%/61,04\%). Traumatismos naquele nível, freqüentemente, manifestam-se sem deficits $(88,4 \%)$. A lesão neurológica acima de $\mathrm{C} 3$, quando ocorre, é freqüentemente fatal ${ }^{9}$.

Mais de $60 \%$ dos pacientes com TRMC C3-C7 apresentaram deficits neurológicos e $41,5 \%$ apresentaram paralisia sem força alguma evidenciável ao exame, com ou sem preservação sensitiva.

Com base nos dados obtidos, podemos estimar o prognóstico para deambulação após TRMC. Considerando os pacientes com potencialidades para deambular (ASIA C, D e E e os quadros centromedulares), 45/77 $(58,4 \%)$ pacientes terão a possibilidade de deambular. Mais de 40\% não deambularão (ASIA A e B).

A proporção de indivíduos com TRMC que morrem direta e precocemente em razão de trauma oscila entre $4 \%$ e $17 \%$. Porém, a proporção de indivíduos que morrem durante a hospitalização aumenta a mortalidade desse traumatismo. Segundo Kraus ${ }^{12}, 21 \%$ morrem nos primeiros dias do trauma durante sua hospitalização inicial, enquanto $48 \%$ morrem antes da alta hospitalar.

Em nossa amostra, 16 (16,8\%) evoluíram para óbito. Entre os pacientes com lesão completa, 39\% dos pacientes com TRM C3-C7 morreram, assim como 100\% ( 2 casos) dos TRM O-C1-C2. Lesões O-C1-C2 causaram mortalidade 6,6 vezes maior que as lesões $\mathrm{C} 3-\mathrm{C} 7$.

Nenhum paciente com preservação de alguma atividade motora evoluiu para óbito.

A maioria dos TRMC O-C1-C2 se localizou em C2 (13/17). A fratura do odontóide tipo II e a fratura do enforcado (espondilolistese traumática) foram as mais freqüentes. $\mathrm{C} 2$ é o centro da movimentação craniocervical, colocando-o vulnerável a lesões.

Os tipos mais freqüentes de TRMC C3-C7 foram a lesão em hiperflexão, seguida da lesão em carga axial e trauma em extensão. O nível mais acometido foi C5; $10,39 \%$ tiveram lesão medular sem lesão óssea nem ligamentar. O diagnóstico de lesão óssea e ligamentar depende do método de análise. Foram usadas a tomografia computadorizada e a radiografia simples. A ressonância magnética não foi disponível na fase aguda.

Dos pacientes O-C1-C2, 47\% puderam ser tratados conservadoramente. $\mathrm{O}$ halo-colete, sistema de órtese mais rígido disponível, foi usado nas lesões instáveis e com grandes chances de não cicatrização. Em 3 pacientes houve complicações que impediram a continuação do uso: perda de parafusos cranianos, infecção e dermatite de contato. Um paciente se recusou a usar halo-colete. Os que não puderam usá-lo foram tratados com colar occipitomandibuloesternal.
O tratamento cirúrgico seguiu o conceito de poupar a movimentação não alterada pelo trauma o máximo possível, para evitar falências de sistemas e dor por imobilização de partes extremamente importantes na mobilidade. Assim, o parafuso no odontóide e o parafuso transarticular $\mathrm{C} 1-\mathrm{C} 2$ foram usados em 4 pacientes. Os retângulos e os sistemas de fixação sublaminares foram usados nos casos irredutíveis.

A via anterior foi usada em todos os pacientes com TRMC C3-C7 e subluxações reduzidas, naqueles com compressão ventral ao saco dural e/ou destruição do corpo vertebral que não tinham contra-indicações para esta.

Pela via posterior, foram operados os pacientes que apresentavam lesões irredutíveis secundárias a bloqueio facetário e/ou contra-indicações para via anterior.

Nos casos de síndrome centromedular, a cirurgia tem sido contra-indicada na fase aguda, pois, freqüentemente, ocorre piora neurológica pós-operatória.

DeVivo 9 achou que lesões $\mathrm{C} 1-\mathrm{C} 3$ causam 6,6 vezes mais mortalidade que as lesões abaixo. Nos seus estudos, a taxa de mortalidade para lesões $\mathrm{C} 4$ ou $\mathrm{C} 5$ e C6 a C8 foram 2,5 e 1,5 vezes maiores, respectivamente, naqueles com paraplegia. Os pacientes em Frankel A tiveram um risco de mortalidade relativo 3,9 vezes maior que aqueles em Frankel D, enquanto aqueles em Frankel $\mathrm{B}$ ou $\mathrm{C}$ tinham um risco de mortalidade relativo de 2,3. Idade, nível e graduação na escala de Frankel são fatores importantes para o prognóstico.

Nenhum paciente com algum grau de movimentação de membros abaixo do nível da lesão obituou. O estado neurológico foi o principal fator prognóstico quad vitae do trauma raquimedular.

\section{Conclusões}

1) A incidência do TRM na zona norte da cidade de São Paulo é de 22,63/milhão/ano, e a do TRMC, 8,6/milhão/ano, menor que a relatada pela maioria dos trabalhos pesquisados.

2) A tendência entre 1997 e 2000 não mostrou diferença significativa, embora a média mensal de casos do ano de 1999 tenha sido 1,84 vez maior que a média de 1996. Essa diferença pode ser importante com relação à previsão de recursos e materiais para o tratamento anual.

3) As causas que provocaram o TRMC neste estudo são diferentes das descritas tradicionalmente, predominando as quedas ao solo, em vez dos acidentes automobilísticos.

4) Nove locais de origem dos pacientes entre os 55 identificados foram responsáveis por mais de um terço dos TRMC. 
5) A média de idade de nossos pacientes foi de 35 anos. Apenas $45 \%$ da amostra apresentava idade inferior a 30 anos.

6) As complicações apareceram em $44,21 \%$ dos pacientes e foram potencialmente graves.

7) A duração média de internação foi de 25,86 dias.

8) As lesões $\mathrm{O}-\mathrm{C} 1-\mathrm{C} 2$ causaram dano neurológico menos freqüentemente que as $\mathrm{C} 3-\mathrm{C} 7(11,6 \%$ / 61,04\%). As lesões completas acima de $\mathrm{C} 3$ foram fatais.

9) Mais de $60 \%$ dos pacientes com TRMC C3-C7 apresentaram deficits neurológicos e 41,5\% apresentaram paralisia, sem nenhuma força evidenciável ao exame, com ou sem preservação sensitiva. Destes, $44 \%$ morreram.

10) Piora neurológica após a internação é ocorrência rara. Um paciente entre os 95 apresentou piora neurológica antes da cirurgia, e outro teve seu quadro neurológico piorado pela cirurgia, com recuperação parcial durante a evolução.

11) O estado neurológico e o nível da lesão foram os fatores prognósticos mais importantes.

12) Os 95 pacientes utilizaram 77 sistemas de fixação e/ou halo-coletes.

\section{Referências}

1. ADAMS VI: Neck Injuries. II. Atlantoaxial dislocations - a pathologic study of 14 traffic fatalities. J Forensic Sci $37: 565-73,1992$

2. AEBI M, ZUBER K, MARCHESI D: Treatment of cervical spine injuries with anterior plating; Indications, techniques, and results. Spine Suppl 16(3): S38-S45, 1990.

3. ANDERSON PA: Principles and techniques of spine surgery. Baltimore, Lippincott, Williams \& Wilkins, 1997, pp 295-330.

4. BOTELHO RB, PALMA AMS, ABGUSSEN CMB, FONTOURA EAF: Traumatic vertical atlantoaxial instability: the risk associated with skull traction. Case report and literature review. Eur Spine J 9:430-3, 2000.

5. CAVALHEIRO JR. Investigação epidemiológica e entrevistas domiciliares. Rev Saúde Públ 15:543-50, 1981.

6. DAVIS D, BOHLMAN H, WALKER E, FISHER R, ROBINSON R: The pathological findings in fatal craniospinal injuries. J Neurosurg 34:603-13, 1971.

7. DE MELLO MT, FERNANDES AC, TUFIK S: Levantamento epidemiológico da prática de atividade física na cidade de São Paulo. Rev Bras Esporte 6:61-98, 2000.

8. DENIS F: The three column spine and its significance in the classification of acute thoracolumbar spinal injuries. Spine 8:817-31, 1983.

9. DE VIVO MJ, RUTT RD, BACK KJ: Trends in spinal cord injury demographics and treatment outcomes between 1973 and 1986. Arch Phys Med Rehabil 73:535, 1992.
10. FRYMOER JW, KRAG MH: The spinal stability and instability: definitions, classifications, and general principles of management. In Dunsker SB, Schmidek $\mathrm{HH}$, Frymoer J, Kahn A (ed): The unstable spine. Ed. 3. Grune \& Stratton, 1996, pp 1-16.

11. GRIFFIN MR, OPITZ JL, KURLAND LT: Mortality, survival and prevalence: traumatic spinal cord injury in Olmsted County, Minnesota, 1935-1981. J Chronic Dis 38:643, 1985.

12. KRAUS JF, SILBERMAN TA, MCARTHUR DL: Epidemiology of spinal cord injury. In Menezes AH, Sonntag VK (ed): Principles of Spinal Surgery. London, McGraw-Hill, 1996, vol. 1, pp 41-58.

13. KRAUSS JF, FRANTI CE, RIGGINS RS et al: Incidence of traumatic spinal cord lesions. J Chronic Dis 28:471, 1975.

14. LEAL FCS, GUIMARÃES ACA, FRANCO RR, VEIGA JCE: Lesões medulares traumáticas agudas sem alterações radiológicas relacionadas com o trauma. Arq Bras Neurocir 18:188-93, 1999.

15. MARSHALL LF, KNOWLTON S, GARFIN SR, KLAUBER MR, EISENBERG HM, KOPANIKY D et al.: Deterioration following spinal cord injury. A multicenter study. J Neurosurg 66:400-4, 1987.

16. MAYNARD FM, WEINARDEN S: Secondary complications of spinal cord injury. In Apple DF, Hudson LM (ed): Spinal Cord Injury: The Model. Proceedings of the National Consensus Conference on Catastrophic Illness and Injury: The Georgia Regional Spinal Injury System, Atlanta, 1989, pp 57.

17. MIRZA SK, KRENGEL WF, CHAPMAN JR, ANDERSON PA, BAILEY JC, GRADY MS et al.: Early versus delayed surgery for acute cervical spinal cord injury. Clin Orthop 359:104-14, 1999.

18. STOVER SL, FINE PR, GO BK: Spinal Cord Injury: The Facts And Figures. University of Alabama Press, Birmingham, 1986.

19. STOVER SL, FINE PR: The epidemiology and economics of spinal cord injury. Paraplegia 25:225, 1987.

20. VACCARO AR, DAUGHERTY RJ, SHEEHAN TP, DANTE SJ, COTLER JM, BALDERSTON RA et al.: Neurologic outcome of early versus late surgery for cervical spinal cord injury. Spine 22:2609-13, 1997.

21. WAI PUI NG, FEHLINGS MG, CUDDY B, DICKMAN C, FAZL M,GREEN B et al.: Surgical treatment for acute spinal cord injury study pilot study \#2: evaluation of protocol for decompressive surgery within 8 hours of injury. Neurosurg Focus 6: 1-9, 1999.

22. WATERS RL, MEYER PR, ADKINS RH, FELTON D: Emergency, acute, and surgical management of spine trauma. Arch Phys Med Rehabil 80:1383-90, 1999.

23. WHITE A, SOUTHWICK WO, PANJABI MM: Clinical instability in the lower cervical spine, a review of past and current concepts. Spine 1:15, 1976.

24. ZIZELI M, OVUL I, TUNCBAY E: A prospective study on acute spinal injuries. Neurosurg Rev 12:107, 1989.

Original recebido em março de 2001

Aceito para publicação em abril 2001

\section{Endereço para correspondência:}

Ricardo Vieira Botelho

Rua Haberbeck Brandão, 68 - ap. 122

CEP 04027-040 - São Paulo, SP

E-mail:bitbot@uol.com.br 


\section{Comentários}

A lesão medular é uma das doenças mais devastadoras para o ser humano e o trauma é a sua causa mais freqüente. Conhecer sua epidemiologia é o primeiro passo para planejar sua prevenção e tratamento. Por esse motivo congratulo os autores pelo excelente trabalho. A incidência de lesão medular estimada para a região Sudeste é de 71 casos por milhão de habitantes, em trabalho realizado com base no ano de $1997^{1}$. Vale ressaltar que os índices do Brasil são altos quando comparados com outros países do mundo, como o Japão e os EUA, nos quais a variação é de 12 a 40/ milhão de habitantes/ano. Considerando que os autores encontraram uma incidência de 22 casos/milhão/ ano, acredito que os números incluem, como é de se esperar, apenas os casos graves que necessitam de internação e transferência para tratamento intensivo. Provavelmente, dois terços dos casos foram tratados nos hospitais de atendimento primário e secundário da região. Os dados apontam que um terço das lesões da coluna vertebral ocorre na região cervical $^{2}$. O que chama a atenção é a causa mais freqüente ter sido a queda, e não o acidente de trânsito. Esse achado é inusitado e dá característica inédita ao trabalho. Justifica uma complementação com um trabalho comunitário detalhado para descobrir as causas das quedas e planejar sua prevenção. Esse achado provavelmente influencia nas características das lesões osteoligamentares encontradas, sua gravidade, complicações e técnica de tratamento. Lembro ter analisado o trauma raquimedular em crianças e observado que as inúmeras lesões por projétil de arma de fogo apresentavam características clínica e terapêutica muito diferentes das outras causas e, por isso, modificavam substancialmente a avaliação estatística do trabalho ${ }^{3}$. Creio que essa diferença (quedas) explique a ocorrência de pacientes com um pouco mais de idade ( $4^{\mathrm{a}}$ década) que a média dos que sofrem acidente de trânsito ( $3^{\text {a }}$ década) e isso deve explicar a maior incidência da lesão centromedular que ocorre em pacientes idosos que associam espondiloartrose cervical e conseqüente canal estreito; provavelmente, o perfil do trabalhador da construção civil no Brasil ${ }^{4}$.

Pacientes com lesão cervical alta geralmente vão a óbito no local do acidente. Os sobreviventes têm pouco ou nenhum deficit ${ }^{5}$. A coluna cervical baixa tem maior número de sobreviventes no período imediatamente após a lesão, mas um alto índice de óbitos tardios em razão de complicações associadas à gravidade da lesão medular. Nesse grupo, a cirurgia, quando indicada, ocorreu em média 12 dias após a internação, o que significa que somente foi realizada após uma avaliação, preparo do paciente e planejamento. A via e a técnica cirúrgica dependem das condições locais e da afinidade da equipe com as instrumentações disponíveis.

Gostaria de enfatizar que o acúmulo de experiência e sua análise metódica é um fator determinante no resultado do tratamento em patologias graves como esta. Por esse motivo, parabenizo os autores, pois sua pesquisa ajuda a consolidar uma unidade de atendimento ao lesado medular grave em uma região de crescente incidência em nosso país.

1. MASINI M: Estimativa da incidência e prevalência da lesão medular no Brasil. Aceito para publicação no J Bras Neurocir, 2001.

2. MASINI M, NETO NGF, NEVES EGC: Experience with a Spinal Cord Unit in Brasilia, Brazil. Paraplegia 28:17-24, 1990.

3. MASINI M, KHAN P, TEIXEIRA MMM, PLANTIER ALM, CANTANHEDE WC, MARANHÃO VL: Trauma raquimedular em crianças. Diferenças na etiopatogenia, tratamento e evolução quando comparado com o adulto. Análise de 160 casos. Arq Bras Neurocir 14:119-28, 1995.

4. MASINI M, SAHARA AH, BARROSO CBRB: Síndrome de lesão centromedular cervical traumática (Schneider). J Bras Neurocir 7:44-52, 1996.

5. NETO NGF, MASINI M, PEREIRA FILHO VD: Tratamento das lesões traumáticas dos segmentos C1/C2 - Analise de 25 casos. J Bras Neurocir 2:80-4, 1990.

Marcos Masini

SHIN QL1 conj 6/ casa 5 CEP 71505-065 Lago Norte, Brasília, DF 